\title{
Numerical investigation of transient single phase forced convection of nanofluids in circular tubes
}

\author{
V. Bianco, O. Manca \& S. Nardini \\ Dipartimento di Ingegneria Aerospaziale e Meccanica, \\ Seconda Università degli Studi di Napoli, \\ via Roma 81031Aversa (CE), Italy
}

\begin{abstract}
In this paper the development of the laminar forced convection flow of a water$\mathrm{Al}_{2} \mathrm{O}_{3}$ nanofluid in a circular tube submitted to a constant and uniform heat flux at the wall is numerically investigated in a transient regime. A single and twophase model (discrete particles model) is employed with either constant or temperature-dependent properties. The investigation is accomplished for a particle size equal to $100 \mathrm{~nm}$. The convective heat transfer coefficient for nanofluids is greater than that of the base liquid. Heat transfer enhancement increases with the particle volume concentration, but it is accompanied by increasing wall shear stress values.
\end{abstract}

Keywords: nanofluid, forced convection, transient numerical analysis.

\section{Introduction}

Convective heat transfer enhancement is a continuous demand in many industrial heating or cooling equipment. An innovative technique for improving heat transfer by using ultra fine solid particles in the fluids has been used extensively during the last decade. Maxwell [1] showed the possibility of increasing thermal conductivity of a mixture by greater volume fraction of solid particles. These fluids, containing colloidal suspended nanoparticles, have been called nanofluids. Nowadays there is a fast growth of research activities in this heat transfer area, as recently reviewed for example in [2-4]. 
Different concepts and models have been proposed to explain the enhancement in heat transfer [5,6]. Experimental results were obtained on convective heat transfer for the laminar and turbulent flow of a nanofluid inside a tube in $[5,7]$. Experimental results for the convective heat transfer of $\mathrm{Al}_{2} \mathrm{O}_{3}$ (27-56 nm)/water based nanofluids flowing through a copper tube in a laminar regime were reported in [8]. Numerical investigations on nanofluids have been carried out by two approaches. The first approach assumes that the continuum assumption is still valid for fluids with suspended nanosize particles. The other approach uses a two-phase model for better description of both the fluid and the solid phases. Another approach is to adopt the Boltzmann theory. The single phase model with physical and thermal properties all assumed to be constant with temperature was employed in [9-13].

The hydrodynamic and thermal characteristics of nanofluids flowing through a uniformly heated tube in both laminar and turbulent regimes with adjusted properties were investigated in [9]. The disadvantages of nanofluids with respect to heat transfer were discussed [10]. It was found that the inclusion of nanoparticles introduced drastic effects on the wall shear stress. A new correlation was proposed in [11] to describe the thermal performance of $\mathrm{Al}_{2} \mathrm{O}_{3}$ water nanofluids under turbulent regime. A numerical study of heat transfer for water $-\mathrm{Al}_{2} \mathrm{O}_{3}$ nanofluids in a radial cooling system was accomplished in [12]. They found that the addition of nanoparticles in the base fluids increased the heat transfer rates considerably. Laminar forced convection flow of nanofluids between two coaxial and parallel disks with central axial injection has been considered using temperature dependent nanofluid properties in [13]. The single phase flow model was solved numerically. A numerical study on the fully developed laminar mixed convection of a nanofluid consisting of water and $\mathrm{Al}_{2} \mathrm{O}_{3}$ in a horizontal curved tube was carried out in [14]. Three-dimensional elliptic governing equations were used and the single phase model was employed. The two phase approach seems a better model to describe the nanofluid flow. In fact, the slip velocity between the fluid and particles may not be zero [5] due to several factors such as gravity, friction between the fluid and solid particles and Brownian forces, the phenomena of Brownian diffusion, sedimentation and dispersion. Very recently, two phase mixture models were applied to study the turbulent forced convection flow of a nanofluid in a uniformly heated tube [15] and in the laminar mixed convection of a nanofluid in a horizontal tube [16]. A comparison between single phase and two phase approaches was accomplished in terms of temperature and velocity distributions and Nusselt number profiles in [17]. The comparison was carried out for steady state developing laminar forced convection flow in a circular tube heated at uniform heat flux.

In this paper the transient laminar forced convection flow of a nanofluid in a circular tube is numerically investigated. A two dimensional axial symmetric flow is considered and the circular tube is heated at uniform heat flux. The study is carried out for water with alumina particles with a spherical size of $100 \mathrm{~nm}$ diameter. The CFD commercial code Fluent is employed to solve the problem by means of the finite volume method. Single phase and two phase approaches are 
employed to evaluate the developing laminar forced convection flow. A comparison between results obtained by two different models is accomplished in terms of temperature and velocity distributions and the surface heat transfer coefficient.

\section{Mathematical modelling}

Figure 1 shows the geometrical configuration under consideration. It consists of the transient, forced laminar convection flow and heat transfer of a nanofluid flowing inside a straight tube of circular cross-section. The basic fluid is water and the particles are of $\mathrm{Al}_{2} \mathrm{O}_{3}$. The tube length is $\mathrm{L}=1.0 \mathrm{~m}$ and it has a diameter $\mathrm{D}=1.0 \times 10^{-2} \mathrm{~m}$. The fluid enters at uniform temperature and axial velocity profiles at the inlet section. The condition of the axially and circumferentially uniform wall heat flux is considered in this study. Also, the flow and the thermal field are assumed to be symmetrical with respect to the vertical plane passing through the tube main axis and the half tube is considered.

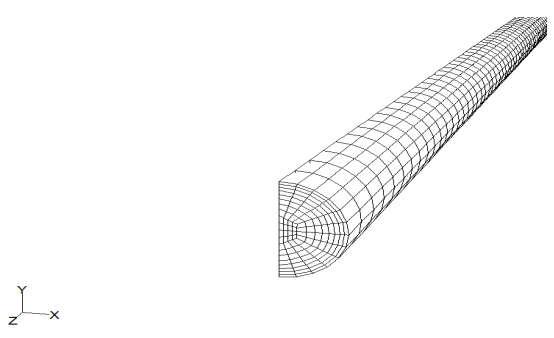

Figure 1: Geometrical configuration under study.

The single phase model, which has been used frequently for nanofluids, is also implemented to compare its predictions with the mixture model. The equations reported in table 1 represent the mathematical formulation of the single phase model.

Table 1: $\quad$ Governing equations.

\begin{tabular}{|c|c|c|}
\hline Mass conservation: & Momentum conservation: & Energy conservation: \\
\hline$\nabla \cdot(\rho \vec{V})=0$ & $\rho \frac{D \vec{V}}{D t}=-\nabla p+\mu \nabla^{2} \vec{V}$ & $\rho c \frac{D T}{D t}=\nabla \cdot(k \nabla T)$ \\
\hline
\end{tabular}

The compression work and the viscous dissipation are assumed negligible in the energy equation.

The same equations are solved for the continuous phase of the two-phase model. Discrete phase is made of spherical particles following the model employed in the Fluent code [18]. The model is given by Ounis et al. [19]. 
At the tube inlet, profiles of uniform axial velocity $\mathrm{V}_{\mathrm{o}}$ (it is calculated from $\mathrm{Re}$, according to the fluid properties) and temperature $\mathrm{T}_{\mathrm{o}}(293 \mathrm{~K})$ prevail. At the tube exit section, the fully developed conditions prevail, that is to say that all axial derivatives are zero. On the tube wall, the usual non-slip conditions are imposed; and one thermal boundary condition has also been considered in this study, namely the uniform wall heat flux. As noted earlier, both the flow and thermal fields are assumed symmetrical with respect to the vertical plane passing through the tube main axis.

The determination of nanofluid properties is, as previously mentioned, at the center of current nanofluid research. For the single phase model the following formulas were used to compute the thermal and physical properties of the nanofluids under consideration (the subscripts $\mathrm{p}$, bf and nf refer to the particles, the base fluid and the nanofluid, respectively).

Density: In the absence of experimental data for nanofluid densities, constantvalue temperature independent densities based on nanoparticle volume fraction are used:

$$
\rho_{n f}=(1-\varphi) \rho_{b f}+\varphi \rho_{b f}
$$

Specific heat: Similarly, in the absence of experimental data relative to nanofluids, it has been suggested that the effective specific heat be calculated using the following equation:

$$
C p_{n f}=(1-\varphi) C p_{b f}+\varphi C p_{p}
$$

Dynamic viscosity: In this work in the first case, dynamic viscosity dependent only on $\varphi$ is considered, then in the second case the variability with the temperature is also considered.

In the first case the dynamic viscosity of nanofluids has been obtained by performing a least-square curve fitting of some scarce experimental data available for the mixtures considered [20-22].

In the second case it is assumed that variable nanofluid properties (with temperature) will yield even better performance predictions than when considering constant properties. In this present work, we have used only experimental data published by [23] as the basis for the properties specified in the numerical model.

Thermal conductivity: As dynamic viscosity in the first case, thermal conductivity dependent only on $\varphi$ is considered, then in the second case the variability with the temperature is also considered.

In the first case the model proposed by [24] has been used, assuming spherical particles. In the second case it is assumed that variable nanofluid properties (with temperature) will yield even better performance predictions than when considering constant properties. The effective thermal conductivity will be based on the experimental data obtained by [23].

For the two phase mode with constant properties the thermophysical properties of $\mathrm{Al}_{2} \mathrm{O}_{3}$ are:

$$
\rho_{\mathrm{p}}=3880 \frac{\mathrm{kg}}{\mathrm{m}^{3}} ; \mathrm{Cp}_{\mathrm{p}}=773 \frac{\mathrm{J}}{\mathrm{kg} \mathrm{K}} ; \mathrm{k}_{\mathrm{p}}=36 \frac{\mathrm{W}}{\mathrm{m} \mathrm{K}}
$$

while the properties of the base fluid are: 


$$
\begin{gathered}
\rho_{\mathrm{bf}}=998.2 \frac{\mathrm{kg}}{\mathrm{m}^{3}} ; \mathrm{Cp}_{\mathrm{bf}}=4182 \frac{\mathrm{J}}{\mathrm{kg} \mathrm{K}} \\
\mathrm{k}_{\mathrm{bf}}=5.97 \frac{\mathrm{W}}{\mathrm{m} \mathrm{K}} \quad ; \mu_{\mathrm{bf}}=9.93 \times 10^{-4} \frac{\mathrm{kg}}{\mathrm{m} \mathrm{s}}
\end{gathered}
$$

\section{Numerical method and validation}

In order to ensure the accuracy as well as the consistency of numerical results, several non-uniform grids have been submitted to an extensive testing procedure for each of the cases considered.

Three different grids have been tested $(20 \times 24 \times 800,10 \times 12 \times 400$ and $5 \times 6$ $x$ 200) in order to get the best trade-off between solution velocity and accuracy.

Results as obtained for a particular test case have shown that for the tube flow problem under consideration, the $10 \times 12 \times 400$ non-uniform grid appears to be satisfactory to ensure the precision of numerical results as well as their independency with respect to the number of nodes used. Such grid has, respectively, 10, 12 and 400 nodes along the radial, tangential (for h covering 0 $180^{\circ}$ ) and axial directions, with highly packed grid points in the vicinity of the tube wall and especially in the entrance region. Different cases have been run for different $\operatorname{Re}(250,550$ and 1050) and various $\mathrm{D} / \mathrm{L}$ ratios (1/50, 1/100 and 1/200).

Moreover an integration time step optimizations has been carried out, particularly three different values $(0.2,0.1$ and $0.05 \mathrm{~s})$ have been tested and at the end the time step of $0.1 \mathrm{~s}$ is chosen because it represents the proper compromise between solution velocity and accuracy.

The computer model has been successfully validated with correlation reported in [25] for thermally and hydraulically developing flow. The CFD commercial code Fluent was employed to solve the problem by means of finite volume method.

\section{Results}

Results were carried out employing the single phase and discrete phase models for $\varphi=1$ and $4 \%, R e=1050$ and $q=10000 \mathrm{~W} / \mathrm{m}^{2}$ either with constant or temperature-dependent properties. In all cases the size of the spherical particles is considered equal to $100 \mathrm{~nm}$.

The simulation has been performed in transient regime simulating $120 \mathrm{~s}$ in order to reach the quasi steady state condition, with an integration time step of $0.1 \mathrm{~s}$.

In fig. 2 it is shown the average wall temperature behaviour in the time for all the models considered with constant properties (Fig. 2a) and variable properties (Fig. 2b) It is possible to observe that increasing the nanoparticles concentration there is a faster transition to the steady state. In the case of constant properties it is shown that there is a slightly difference between the single phase and the discrete model, while in the variable properties model this difference is 


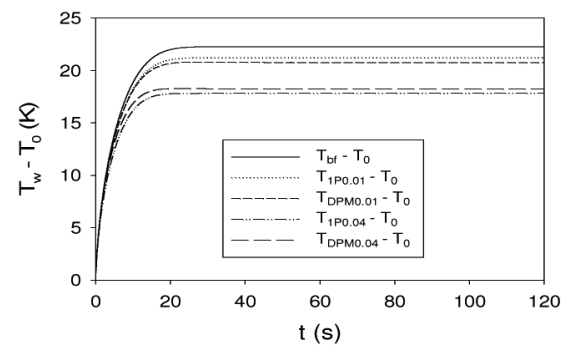

(a)

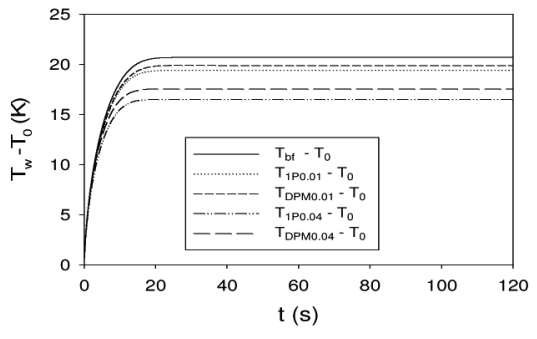

(b)

Figure 2: $\quad$ Average wall temperature: (a) constant and (b) variable properties.

amplified, particularly at the increasing of nanoparticles concentration. The average wall temperature reached by the constant properties model are slightly higher than the ones reached in the variable properties model.

In fig. 3 it is presented the ratio between the average surface heat transfer coefficient in the presence of nanofluid and the one of the basic fluid (water), both in the cases of constant (a) and variables (b) properties. It is possible to observe that both in Fig 3 (a) and (b) for $\varphi=1 \%$ there is an increment of the surface heat transfer coefficient around $5 \%$, while for $\varphi=4 \%$ there is an increase in the heat transfer coefficient around $20 \%$.

So it is possible to notice how strong is the heat transfer enhancement due to nanoparticles effect, also at relative small concentrations.

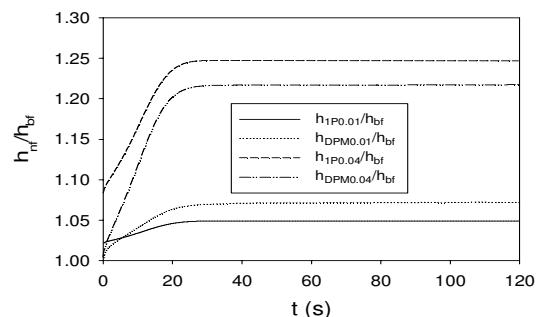

(a)

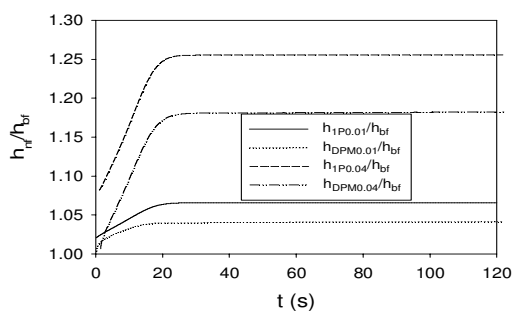

(b)

Figure 3: Surface heat transfer coefficient ratio: (a) constant and (b) variable properties.

In Fig 4 it is presented the temeperature profile along the wall for the cases with constant (a) and variable (b) properties after $120 \mathrm{~s}$.

As for the case of constant properties, (Fig. 4a), it is observed that there is a very slight difference in the wall temperature for $\varphi=1 \%$ for the one phase and discrete phase model, instead for $\varphi=4 \%$ this difference is more evident, particularly the one phase model leads to lower wall temperature.

In the case of variable properties (Fig. 4b), it is shown an appreciable differences between one phase and discrete model for both $\varphi=1 \%$ and $4 \%$. 
In Fig. 5 it is shown the ratio between the local surface heat transfer coefficient with nanofluids and without nanofluids, the base fluid, along the longitudinal axes after 120s for the two considered cases (constant (a) and variable (b) properties). It is shown that near the inlet section, in the case of the discrete phase model for $\varphi=1 \%$ and $4 \%$ and for constant and variable properties, a peak which converge to a nearly constant value at $\mathrm{z} / \mathrm{L}=0.4$. In the case of single phase model, the ratio, after a slight overshoot in the inlet part $(\mathrm{z} / \mathrm{L}<0.1)$, tends to grow in a linear way until the outlet section. The discrete phase and single phase almost present the same value for $\varphi=1 \%, z / L>0.5$ and constant properties (Fig. 5 a), while in the other cases there are more marked differences between the two model, which are around the $10 \%$; particularly the single phase model presents higher values.

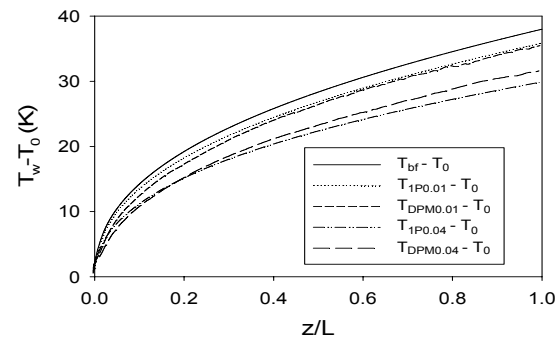

(a)

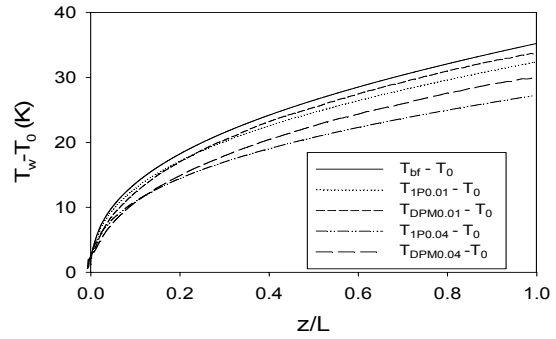

(b)

Figure 4: Wall temperature profile at $\mathrm{t}=120 \mathrm{~s}$ : (a) constant and (b) variable properties.

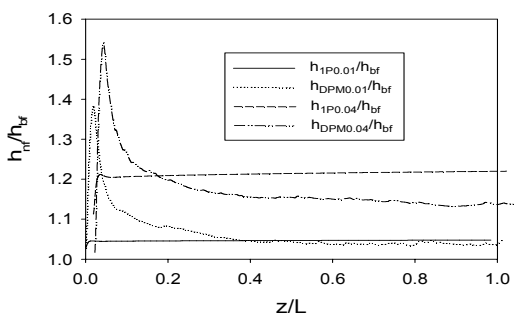

(a)

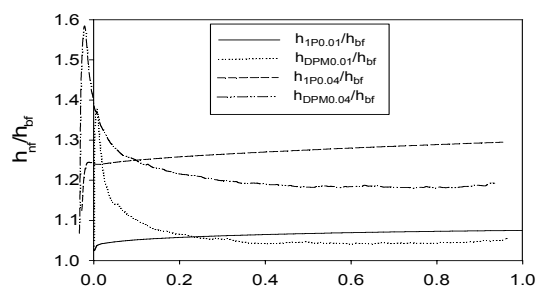

$(\mathrm{b})^{\text {2/L }}$

Figure 5: Local surface heat transfer coefficient after 120s: constant (a) and variable (b) properties.

In Fig. 6 the axial velocity profiles, for $\mathrm{z} / \mathrm{L}=0.5$ and $\mathrm{t}=120 \mathrm{~s}$, are presented for the constant (a) and variable (b) properties cases. In both cases the highest velocity values are detected for $\varphi=4 \%$ and in the case of variable properties the single and discrete phase models give, practically, the same results, whereas in the case of constant properties there are slight differences only for $r / r_{0}<0.5$. Also for $\varphi=1 \%$ the single and discrete phase profiles are very close. 


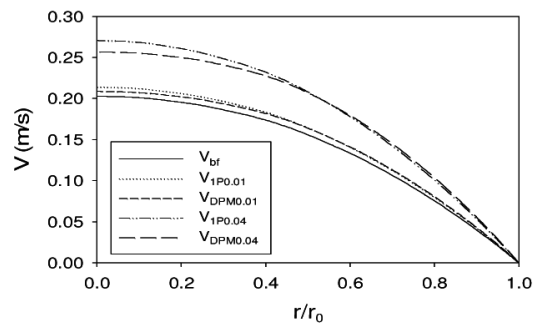

(a)

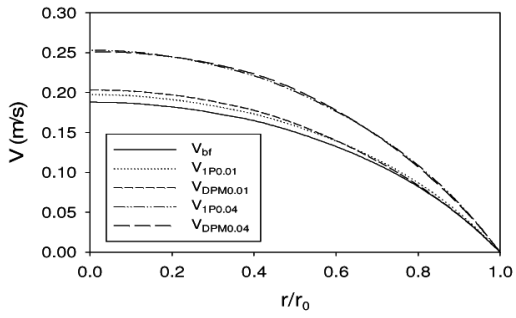

(b)

Figure 6: Axial velocity profile at $\mathrm{z} / \mathrm{L}=0.5$ and $\mathrm{t}=120 \mathrm{~s}$.

Table 2: $\quad$ Shear stress ratios comparison.

\begin{tabular}{|c|c|c|c|c|}
\hline \multirow{2}{*}{} & \multicolumn{2}{|c|}{ Constant Properties } & \multicolumn{2}{c|}{ Variable Properties } \\
\cline { 2 - 5 } & $1 \mathrm{P}$ & $\mathrm{DPM}$ & $1 \mathrm{P}$ & $\mathrm{DPM}$ \\
\hline$\tau / \tau_{\mathrm{bf}}(\varphi=1 \%)$ & 1.14 & 1.16 & 1.18 & 1.12 \\
\hline$\tau / \tau_{\mathrm{bf}}(\varphi=4 \%)$ & 1.99 & 1.54 & 1.97 & 1.52 \\
\hline
\end{tabular}

In table 1 , the ratio between average shear stress after $120 \mathrm{~s}$ in presence of nanoparticles and the one of the base fluid is shown. It is possible to observe how it increases with the nanoparticles volume concentration.

\section{Conclusions}

In this paper the fluid-dynamic and thermal behaviours of water- $\mathrm{Al}_{2} \mathrm{O}_{3}$ nanofluids flowing inside a tube heated at uniform heat flux were numerically investigated in transient conditions and for laminar flow. Four models were employed: single and two-phase models with either constant or temperaturedependent properties. Results clearly showed that the inclusion of nanoparticles produced a considerable increase of the heat transfer with respect to that of the base liquid. Heat transfer enhancement was increasing with the particle volume concentration. However it was accompanied by increasing wall shear stress values, so it is important to evaluate the trade-off between heat transfer enhancement and shear stress increase.

\section{Nomenclature}

Cp Specific Heat of the fluid, $\mathrm{J} / \mathrm{kgK}$

D Tube diameter, $\mathrm{m}$

d Particles diameter, $m$

h Heat transfer coefficient $(\mathrm{h}=\mathrm{q} / \mathrm{(T}$ $\left.\mathrm{T}_{0}\right) \mathrm{W} / \mathrm{m}^{2} \mathrm{~K}$

$\mathrm{k}$ Thermal conductivity of the fluid $\mathrm{W} / \mathrm{mK}$ r Radial coordinate, $\mathrm{m}$

$\mathrm{r}_{0} \quad$ Tube radius, $\mathrm{m}$

Re Reynolds number,

$\mathrm{Re}=\mathrm{V}_{0} \mathrm{D} / \mu$

$\mathrm{t}$ Time, $\mathrm{s}$

T Fluid temperature, $\mathrm{K}$ 


$$
\begin{array}{cl}
\mathrm{L} & \text { Tube length, } \mathrm{m} \\
\mathrm{P} & \text { Pressure, } \mathrm{Pa} \\
\mathrm{q} & \text { Wall heat flux, } \mathrm{W} / \mathrm{m}^{2} \\
\text { Greek } & \text { Symbols } \\
\varphi & \text { Particle volume concentration } \\
\mu & \text { Fluid dynamic viscosity, } \mathrm{kg} / \mathrm{ms}
\end{array}
$$

\section{Subscripts}

$\begin{array}{ll}\text { av } & \text { average value } \\ \text { bf } & \text { Refers to base-fluif } \\ \text { nf } & \text { Refers to nanofluid property }\end{array}$

DPM Discrete Phase Model
$\begin{array}{ll}\mathrm{V} & \text { Axial velocity, } \mathrm{m} / \mathrm{s} \\ \mathrm{z} & \text { Axial coordinate, } \mathrm{m}\end{array}$

$\begin{array}{ll}\rho & \text { Fluid density, } \mathrm{kg} / \mathrm{m}^{3} \\ \tau & \text { Wall shear stress, } \mathrm{Pa}\end{array}$

$\mathrm{p}$ Refers to particle property

w Value at wall

0 Refers to reference condition

$1 \mathrm{P}$ Mono Phase

\section{Acknowledgements}

This work was supported by SUN with a 2007 grant and MUR with the "EliosLab" program.

\section{References}

[1] Maxwell, J.C., A Treatise on Electricity and Magnetism, second ed., Oxford University Press, Cambridge, 1881

[2] Eastman, J.A., Phillpot, S.R., Choi, S.U.S., \& Keblinski, P., Thermal transport in nanofluids, Annu. Rev. Mater. Res., 34, pp.219-46, 2004.

[3] Keblinski, P. Eastman, J.A., \& Cahill, D.G., Nanofluids for thermal transport, Materials Today, 8 (6), pp. 36-44, 2005.

[4] Das, S. K., Choi, S. U. S., \& Patel, H. E., Heat transfer in nanofluids-a review, Heat Transfer Engineering, 27 (10), pp. 3-19, 2006.

[5] Buongiorno, J., Convective transport in nanofluids, ASME J. Heat Transfer, 128, pp. 240-250, 2006.

[6] Wang, X.-Q., \& Mujumdar, A. S., Heat transfer characteristics of nanofluids: a review, Int. J. Thermal Sciences, 46, pp. 1-19, 2007.

[7] Keblinski, P., Phillpot, S.R., Choi, S.U.S., \& Eastman, J.A., Mechanisms of heat flow in suspensions of nano-sized particles (nanofluid), Int. J. Heat Mass Transfer, 45, pp. 855-863, 2002.

[8] Pak, B.C., \& Cho, Y.I., Hydrodynamic and heat transfer study of dispersed fluids with submicron metallic oxide particles, Exp. Heat Transfer, 11, pp. 151-170, 1998.

[9] Xuan, Y.M., \& Li, Q., Investigation on convective heat transfer and flow features of nanofluids, J. Heat Transfer 125, 151-155, 2003.

[10] Wen, D., \& Ding, Y., Experimental investigation into convective heat transfer of nanofluids at the entrance region under laminar flow conditions, Int. J. Heat Mass Transfer, 47 (24), pp. 5181-5188, 2004. 
[11] Maiga, S.E.B., Nguyen, C.T., Galanis, N., \& Roy, G., Heat transfer behaviours of nanofluids in a uniformly heated tube, Superlattices Microstruct., 35, pp. 543-557, 2004.

[12] Maiga, S.E.B., Palm, S.J., Nguyen, C.T., Roy, G., \& Galanis, N., Heat transfer enhancement by using nanofluids in forced convection flows, Int. J. Heat Fluid Flow, 26 (4), pp. 530-546, 2005.

[13] Palm, S.J., Roy, G., \& Nguyen, C.T., Heat transfer enhancement with the use of nanofluids in radial flow cooling systems considering temperature dependent properties, Appl. Thermal Eng., 26, pp. 2209-2218, 2006.

[14] Akbarinia, A., \& Behzadmehr, A., Numerical study of laminar mixed convection of a nanofluid in horizontal curved tubes, Appl. Thermal Eng., 27, pp. 1327-1337, 2007.

[15] Behzadmehr, A., Saffar-Avval, M., \& Galanis, N., Prediction of turbulent forced convection of a nanofluid in a tube with uniform heat flux using a two phase approach, Int. J. Heat Fluid Flow, 28, pp. 211-219, 2007.

[16] Mirmasoumi, S., \& Behzadmehr, A., Numerical study of laminar mixed convection of a nanofluid in a horizontal tube using two-phase mixture model, Applied Thermal Engineering, 28, 717-727, 2008.

[17] Chiacchio, F., Manca, O., \& Nardini, S., Numerical investigation of single phase forced convection of nanofluids in circular tubes, Proc. 2007 ASMEJSME Thermal Engineering Conference and Summer Heat Transfer Conference, paper HT2007-32855, July 8-12, 2007, Vancouver, BC, Canada, 2007.

[18] Fluent Incorporated, Fluent 6.2, User Manual, 2006.

[19] Ounis, H., Ahmadi, G., \& McLaughlin, J. B., Brownian diffusion of submicrometer particles in the viscous sublayer, J. Colloid Interface Science, 143 (1), pp. 266-277, 1991.

[20] Masuda, H., Ebata, A., Teramae, K., \& Hishinuma, N., Alteration of thermal conductivity and viscosity of liquid by dispersing ultra-fine particles (dispersion of $\gamma-\mathrm{Al} 2 \mathrm{O} 3, \mathrm{SiO} 2$ and $\mathrm{TiO} 2$ ultra-fine particles), Netsu Bussei (in Japanese), 4 (4), pp. 227-233, 1993.

[21] Lee, S., Choi, S.U.-S., Li, S., \& Eastman, J.A., Measuring thermal conductivity of fluids containing oxide nanoparticles, J. Heat Transfer, 121, pp. 280-289, 1999.

[22] Wang, X., Xu, X., \& Choi, S.U.-S., Thermal conductivity of nanoparticlesfluid mixture, J. Thermophys. Heat Transfer, 13 (4), pp. 474-480, 1999.

[23] Putra, N., Roetzel, W., \& Das, S.K., Natural convection of nanofluids, Heat Mass Transfer, 39, pp. 775-784, 2003.

[24] Hamilton, R.L., \& Crosser, O.K., Thermal conductivity of heterogeneous two-component systems, I \& EC Fundamentals, 1 (3), pp. 187-191, 1962.

[25] Churchill, S.W., \& Ozoe, H., Correlations for forced convection with uniform heating in flow over a plate and in developing and fully developed flow in a tube, J. Heat Transfer, 95, pp. 78-84, 1973. 